\title{
Sequential information seeking: Effects of the number of terminal acts and prior information'
}

\author{
David M. Messick \\ UNIVERSITY OF CALIFORNLA, SANTA BARBARA
}

\begin{abstract}
An experiment was conducted by a digital computer in which human Ss had the task of sequentially sampling from a binomial universe containing a proportion, $p$, "top quality" items. The S could stop sampling at any point to make a terminal decision by selecting the one of $s$ mutually exclusive and exhaustive subsets of the unit interval which he believed contained $\mathrm{p}$. The four experimental treatments were defined by crossing two partitions of [0-1], one involving 3 terminal acts, the other having 5 , and two prior frequency distributions. Analysis of variance of the number of predecision observations taken indicated (a) significant individual differences, (b) significant $\mathrm{S}$ by treatment interactions, (c) differences attributable to the decision partitions with more observations being taken in the 5 act case than in the 3 act case, and (d) no effect of prior frequency distributions.
\end{abstract}

\section{Introduction}

The study of human decision making has engendered interest in the related problem of human information processing. One aspect of this problem, namely, how much information does a person require prior to making a decision, has received considerable attention in the past decade. Studies by Irwin and Smith $(1956,1957)$, Becker (1958), Pruitt (1961), Lanzetta \& Kanareff (1962) and Driscoll \& Lanzetta (1964) have investigated a number of factors which influence the amount of information taken prior to decision. The results of these studies have suggested that human information seeking is "rational" in coarse features at least. The present study is designed to investigate the effect of two additional variables on predecisional information seeking: the number of terminal acts and the information available to the decision maker prior to his beginning the task. From the point of view of Bayesian decision theory both of these variables are important in determining how much information "should" be observed prior to making a decision. In general, the larger the number of terminal acts, the more predecision information is needed, and the more prior information available about which of the terminal acts is correct, the less current information need be observed. ${ }^{2}$

\section{Subjects}

The subjects (Ss) were 54 male undergraduates enrolled in the University of North Carolina. The Ss were all selected from a subject pool being developed for studies in human decision making. Instruetions

All Ss were asked to imagine that they were employed by a canning factory. The following is a summary of the instructions. "Your job is to have incoming shipments of produce inspected to determine the proportion of 'top quality' items in each shipment. For each type of produce which might be encountered (e. g., tomatoes, cucumbers, etc.) the company has a grading policy which depends on the uses to which the product can be put. For example, tomato soup is made from shipments having fewer than 20 percent top quality tomatoes. From shipments having between 20 and 50 percent top quality items, tomato paste and tomato ketchup are made. Shipments having 90 percent or more top quality items go into the Grade A canned tomatoes. For each shipment you will be informed of the company policy to use. In Table 1 are listed the 3 company policies you will use today.

"After you grade a shipment, it is immediately processed and the actual proportion of top quality items is determined. If the shipment was correctly graded you are paid a bonus of 15 cents. However, each item that you have inspected will cost you $1 / 5$ of a cent. This method of payment has been devised by the company because the more money you make, the more the company makes. Thus the company wants you to try to make as much money as possible.

"To aid you in your work, the company keeps a record of the proportions of top quality items found in the past 300 shipments of each of the commodities you will inspect today, this past record will be available."

\section{Procedure and Apparatus}

The $\mathrm{S}$ entered the experimental room which houses a Royal McBee LGP-30 digital computer. He read the instructions and sat down facing a Friden Flexowriter connected to the computer. The experimenter (E) started the program and the computer printed out the following:

The following is the record for the past 300 shipments

of the commodity with which you will now be working:

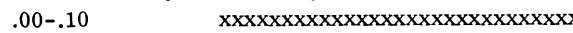

$.10-.20 \quad \mathrm{xxxxxx \times x \times x \times x \times x \times x \times x \times x \times x \times x \times x \times xx}$

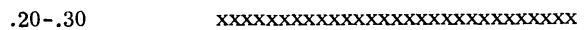

$.30-.40 \quad \mathrm{xxxx \times x \times x \times x \times x \times x \times x \times x \times x \times x \times x \times xxx}$

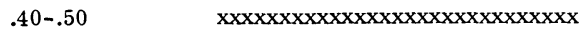

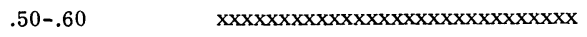

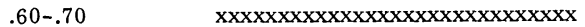

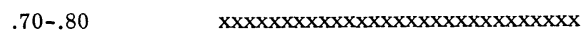

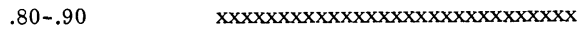

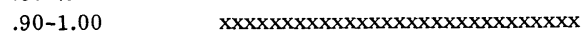

For the following shipments:

Inspection is sequential.

For the following shipments:

Company policy requires that you choose one of these intervals $[.00 \overline{\mathrm{a}} .50] \quad\left[.50{ }_{\mathrm{b}}{ }^{1.00}\right]$

For the following shipments:

A correct choice is worth $\quad .1500$

An incorrect choice costs $\quad .0000$

Each piece inspected costs $\quad .0020$

(The rectangular prior distribution was presented first to one-half of the Ss. The other half first encountered the skewed distribution which had frequencies of $0,0,3,12,28,51,74,50$, and 11).

This information was interpreted for $S$ to make certain that he understood the task. $\mathrm{S}$ was then shown that by pressing the "start compute" button on the typewriter, the computer would print either a " 1 " indicating that the item inspected was "top quality" or a " $0, "$ indicating that it was not. Then the proportion of "top quality" items

Table 1. Company Policies Used in the Experiment

$$
\begin{aligned}
& \text { 1. }[.00-.50][.50-1.00] \\
& \text { 2. }[.00-.33][.33-.67][.67-1.00] \\
& \text { a } \frac{b}{c} \\
& \text { 3. }[.00-.20][.20-.40][.40-.60][.60-.80][.80-1.00]
\end{aligned}
$$


in the sample to that point was printed. When $\mathrm{S}$ was ready to make a decision he typed the letter corresponding to the interval he wished to choose and pressed the "start compute" button. The machine then printed the true proportion for that trial, .1500 or .0000 (depending on whether $\mathrm{S}$ was correct or incorrect), $-.02 \mathrm{n}$ (minus the cost of the sample), the net amount gained on that trial, and S's total earnings up to that point. A trial ended with a decision.

In addition to storing data and conducting the experiment, the computer, using a random number generator, selected values for $p$, the true proportion for each trial. These values were selected with probabilities specified by Beta density functions in which $f(p)=B(a, b)^{-1}$ $\mathrm{p}^{\mathrm{a}-1}(1-\mathrm{p})^{\mathrm{b}-1}$. For the uniform distribution $\mathrm{a}=1, \mathrm{~b}=1$, while $\mathrm{a}=6$, $b=3$ for the skewed one. Once the value of $p$ was selected, the computer generated a " 1 " with probability $\mathrm{p}$ and " 0 " with probability 1-p each time $S$ requested another observation.

\section{Design}

Company policy 1 was used for 3 practice trials. Thereafter only policies 2 and 3 were used. Each subject had 8 trials with each of the 4 combinations of prior distribution and company policy giving a total of 32 trials. (The computer automatically informed $\mathrm{S}$ after every 8 trials when a change in the decision context occurred.) For the first 16 trials $\mathrm{S}$ used one prior distribution. The other was used for the last 16 trials. Under this restriction there are 8 different sequences of the 4 experimental conditions. The Ss were randomly assigned to sequences. The number of Ss in each sequence was either 6,7 , or 8 .

\section{Results}

For each $\mathrm{S}$ the total number of observations taken prior to decision under each treatment was recorded. To allow for the evaluation of subject by treatment interactions, this total was split into the total for even numbered trials and the total for odd numbered trials. In order to obviate the assumption of equal variancecovariance matrices for different sequences of treatments, separate analyses were conducted for each of the 8 sequences.

For all 8 groups, the between Ss variation was significant well beyond the .01 level. The average number of observations per trial for all Ss is 9.09. The range extends from .25 observations per trial to 22.59 per trial. In addition, the interaction between Ss and the four experimental treatments was significant beyond the .01 level in 7 of the 8 groups. Thus, Ss differed not only in terms of the total number of observations taken, but also in their responses to the specific experimental conditions.

In all but 2 of the 8 groups, the company policy contributed a significant source of variation. In every group more observations were taken with the 5 alternative policy than with the 3 alternative one. Averaging over all groups, the mean number of observations with the 3 alternative case is 8.23 while that for the 5 alternative scheme is 10.16 .

The prior information (the frequency distributions) contributed a significant source of variation in only 3 of the 8 groups. The apparent unreliability of these results is enhanced by the fact that in 2 of these groups Ss took more observations with the skewed distribution, while in the other Ss took more observations with the flat prior. This contradiction is readily explained. In all groups, one prior was used for the first 16 trials and the other was used for the last 16 trials. Differences between prior distributions are therefore confounded with any systematic trends, e. g., learning, which might operate as a function of time. Just such a systematic effect does appear to be responsible for the differences between prior distributions. First, in every group, more observations were taken in the last 16 trials than in the first 16. Second, the difference between the mean number of observations for the first 16 trials and that for the last 16 trials does not depend on which of the prior distributions is presented first.

\section{Diseussion}

It is somewhat of a puzzle that the prior frequency distributions did not affect the number of observations taken before decision. Certainly the skewed distribution provided less uncertainty about $p$ than did the flat distribution. However, Ss did not appear to make use of this information in deciding how many observations to take. There are at least two possible explanations of this finding. First, the results might reflect the tendency of humans to use probabilistic information inefficiently. Edwards (1964) reports that Ss often fail to reach the degree of certainty in opinions which is justified by data. It is possible that Ss in this experiment did not consider the difference in the prior distributions to be large enough to warrant their making adjustments to account for the difference. On the other hand, it is possible that Ss "should" have taken as much information under the skewed prior as with the rectangular one. This possibility follows from the fact that the skewed prior has a smaller variance than the rectangular. Consequently, the probability of values of $p$ close to 0 or 1 is smaller with the skewed than with the rectangular prior. Thus homogeneous samples, i. e., samples composed entirely of 1 's or 0 's, are more likely under the rectangular prior. As a general rule (which applies to the two company policies used in this experiment) one should stop sampling sooner if the obtained sample is homogeneous than if it is not. This possibility will be evaluated in detail when optimal information seeking strategies have been applied to this task. Refereneé:

BECKER, G. M. Sequential decision making: Wald's model and estimates of parameters. J. exp. Psychol., 1958, 55, 628-636.

DRISCOLL, J. M., \& LANZETTA, J. T. Effects of problem uncertainty and prior arousal on predecisional information search. Psychol. Rep., 1964, 14, 975-988.

EDWARDS, W. Optimal strategies for seeking information: Models for statistics, choice reaction times, and human information processing. Institute of Science and Technology Report. 3780-21-J, 1964, University of Michigan.

IRWIN, F. W., \& SMITH, W. A. S. Further tests of theories of decision in an "expanded judgment" situation. J. exp. Psychol., 1956, $52,345-348$.

IRWIN, F. W., \& SMITH, W. A. S. Value, cost and information as determiners of decision. J.exp. Psychol., 1957, 54, 229-232.

LANZETTA, J. T., \& KANAREFF, V. T. Information cost, amount of payoff, and level of aypiration as determinants of information seeking in decision making. Behav. Sci., 1962, 7, 459-473.

PRUITT, D. G. Informational requirements in making decisions. Amer. J. Psychol., 1961, 74, 433-439.

\section{Notes}

1. This research was supported by the United States Air Force, Electronic Systems Division, Contract No. AF-19-(628)-1610.

2. This is an exceedingly gross statement of predictions which can be derived from the Bayesian position. 